\title{
Sul verbo redire
}

\section{Luca Serianni}

PUBBLICATO: 17 SETTEMBRE 2019

\section{Quesito:}

Manuel B. e Orsola P. ci chiedono della coniugazione e dell'uso del verbo redire (riedere).

\section{Sul verbo redire}

I 1 verbo redire è un arcaismo, del tutto uscito d'uso. La base è il lat. redire, del quale l'italiano antico ha usato, soprattutto in poesia, solo alcune forme. Una di queste è riede (lat. rědit, col normale dittongamento che si ha in sillaba libera): "che dopo 'l sogno la passione impressa / rimane, e l'altro a la mente non riede", nei famosi versi di Par. XXXIII, 59-60 in cui Dante evoca l'istante in cui ha avuto la visione di Dio; "se mai non riede" (Petrarca, Rerum vulg. fragm., 2436 'se non tornerà più da me'). Nella letteratura più tarda, del Sei-Settecento, si è generata la forma artificiale riedere, sul modello di chiede-chiedere, che però continuano legittimamente il lat. quaerit quaerere. La vicenda di redire/riedere è speculare a quella di un altro verbo arcaico: fedire/fiedere. La base è il lat. ferire: nell'italiano antico si era affermata la forma dissimilata fedire (come del resto è avvenuto anche inquaerere) e anche fedire ha generato per via analogica, forme artificiali come fiede, fiedono; ancora in un'odicina barbara di Carducci, Figurine vecchie, si legge: "di torbid'ire fiedere l'aere".

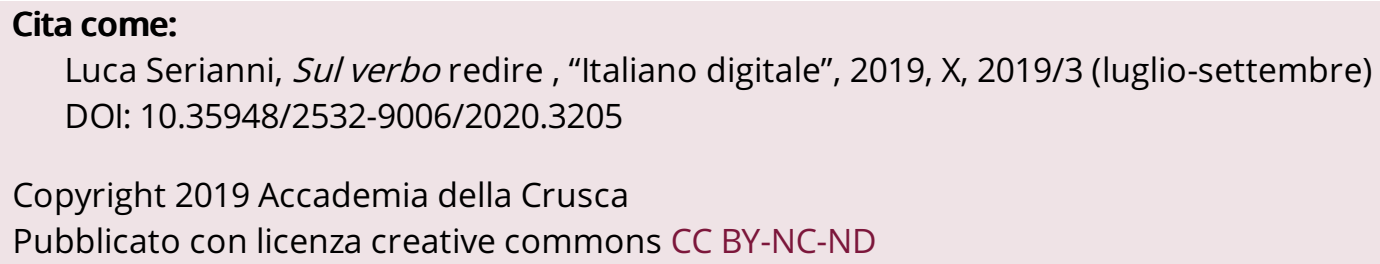

